\title{
Practical and Innovational Ability's Research and Cultivation of Local Colleges Applied Statistics Major under Transformation Background
}

\author{
HOU Zong-yi \\ School of Mathematics and Statistics \\ Hechi University \\ Guangxi, Yizhou 546300, P. R. China \\ hcxyhouzongyi@163.com
}

\author{
WEI Yan-xiao \\ School of Mathematics and Statistics \\ Hechi University \\ Guangxi, Yizhou 546300, P. R. China \\ Weiyanxiao1@163.com
}

\begin{abstract}
Under the background that the center government put classification reform to higher education, the local colleges only respond to country's call and carry out the transformation reform, then can cultivate the applied talents with practical and innovational ability to service the development of local society and economy better. Combining the characteristics of local colleges, this article will discuss the cultivation methods of improving the ability of Applied Statistics majors, supplying effective reference for transformation reform of local colleges and universities
\end{abstract}

Keywords-transformation development; practice and innovation Ability; applied statistics research; ability training

\section{INTRODUCTION}

The transformation of economic development model and the tendency of industry transformation and upgrade force higher education carry out classified reformation, requiring a higher educational structure which is matched to the economic industrial structure[1]. Therefore, local colleges and universities only promote the transformation development through comprehensive reforms then can cultivate applied creative talents who are badly in need of the regional economic construction. Combining the reality of local colleges and universities, this article will discuss the practical and creative abilities' cultivation methods of Applied Statistics majors under the transformation background, supplying college a reference of optimizing higher education's structure, quality and revising the education scheme of Applied Statistics' talents, which will benefit promoting the overall transformation work.

\section{Practical And Creative Abilities of ApPlied STATISTICS MAJORS}

Applied Statistics is a new major integrated Statistics with Economics, Management and Computer Science. This major is aimed to cultivate students' comprehensive quality of morality, knowledge and physicality with high political quality, good professional ethics, strong Mathematics and Applied Statistics theory, mastering modern statistics science and computer application, so that they can not only be engaged in economic, management, biology, medicine, finance, insurance, education and other related work, but also have innovation spirit and practical ability, letting them adapt to the development requirement of socialist market economy and information society[2]. Therefore, the innovational and practical ability that this article studies is referred to the ability that the Applied Statistics majors should master during the undergraduate course studying to adapt to local economic and social development requirement. It can be divided into two aspects as follow:

\section{A. Social Practical Ability The practical ability to conduct} social activities.

Students majoring in Applied Statistics in local colleges and universities should cultivate their ability to solve problems in social practices. This relies mainly on their participation in social activities, which is achieved by their own efforts, creative discoveries or inventions, and ability to formulate and adjust reform schemes[3]. It involves mainly the ability to identify, analyze, and solve problems, and the capacity of innovative cooperation, expression and communication, organization and management.

\section{B. The ability to practice professional skills}

Professional skills refer to the professional competency and fundamental skills of students to work as they are cultivated according to their major. Professional skills result from specializing training based on general knowledge course as well as professional theory learning, representing a necessity for students to find a job and a guarantee for their successful career. As for students majoring in Applied Statistics, practical training will lead to professional skills for jobs of applied statistics industry, which includes the ability to collect data, research, analyze the data, conduct modeling, estimation, and composition.

\section{The Problems of Local Colleges AND Universities' Cultivating ApPliEd Statistics Majors' PracticAl AND INNOVATIONAL ABILITY}

Most of local colleges and universities set up the Applied Statistics based on the Statistics, which induces the students' relatively weak basis and practical ability, such they are not 
very welcome to the employer as they will take longer time to adapt new position Abbreviations and Acronyms

\section{A. Relatively Short Practical Teaching Period}

Practice is the driving source of motivating and directing student to study and acquire knowledge, and also is the necessary condition of transforming knowledge into ability, but in the cultivating scheme of the local colleges' Applied Statistics, the teaching period allocation between theory and practice is not very scientific, such as the practical teaching period is not enough to smoothly carry out the practical teaching comprehensively.

\section{B. Relatively Single Practical Teaching Mode}

Practical teaching is very weak and the social practical is just only a formality. Practical teaching is still mainly at the internship level, being carried out at practice base by the employee there only. It is mainly related to some simple work without any technical content. The graduates of the colleges that are without practice base need to contact internship units for practice by themselves, leading to some false practice report and wasting the precious practical chance and time. The requirement of graduation thesis (design) is not much, lacking practical part. Thus, graduates get it pass easily, which can't reach the effect that it deserves.

\section{Relatively Limited Teachers' Practical Ability}

Most of the teachers are very young. They lack of practical experience in enterprises and their attention and participation of practical teaching is not enough. Compared to method's application and operation, they pay more attention on theory teaching, such they don't have strong practical ability, which induces that students are very familiar with the formulas and concepts and can get good test results but lack ability of analyzing and solving practical problem independently; what's more, the students can't combine related theory to analyze and solve specific problems in practical work; such students lack of practical application and operational ability.

\section{Cultivation Strategy of Application Statistics}

MAJORS' PRACTICAL AND INNOVATIONAL ABILITY UNDER THE TRANSFORMATION BACKGROUND

Improving practical and innovational ability of Applied Statistics majors needs teachers' cultivation, guarantee of teaching management, and also depends on the internal cause of students' self-efforts. Therefore, strengthening practical teaching, increasing scientific research training and social practice and improve the ability of college students' life management so that the students' practical and innovational ability can be improved.

\section{A. Improve the talents' developing plan}

Social demand has determined the orientation of talents' development, thus determined its goal, which also represents the foundation of the establishment of the specialized subject. Confirming to the principle of "a wider resource, a stable foundation, and a focus on application", the subject of Applied Statistics in local colleges and universities incubate specialized personnel[4]. The students are supposed to cater to the market demand, mastering a rich knowledge and a strong ability of application in a certain field and at the same time able to operate a number of statistical analysis software. Consequently, they become experts in one field while possessing all-round knowledge and ability that could guarantee their employment. Therefore, local enterprises should be invited in the formulation of the talents' developing plan to diagnose and assess this subject, improve the plan, thus establishing a developing pattern that integrates the industry, education and practice.

\section{B. Optimizing Courses’ Teaching Contents}

Local colleges need to invites experts of related industries and enterprises to participate in Applied Statistics' modular curriculum reform, so that courses' contents can be matched to occupational standard. Teaching period between theory and practice needs to be distributed scientifically. It also needs to set practical teaching standard in classification, increase practical teaching proportion, strengthen practical teaching and provide institutional guarantee for improving students' practical and innovational ability.

\section{Reforming Classroom Teaching Mode}

The major courses' teaching mode needs reforming with research-style cases teaching methods. Teaching cases and strategy should be edited and designed according to major background and students' interests, abstracting the concrete problems facing in practice to statistics cases to reasonably explain and deeply research by exploring and analyzing related cases, solving problems and flexible application and organically combining teachers' guidance, students' interests and teaching materials' demonstration effect together, which will be the necessary supplement for theoretical knowledge, improve teaching performance greatly and effectively cultivate students' finding, analyzing and solving problems' ability.

\section{Broaden the practice bases}

In order to improve the ability of the application of statistical professional students how to use professional knowledge to solve practical problems, the school should be expand the new practice and training base, expand the offcampus practice space, seek cooperation with schools around the government, enterprises, construct firm consistent training and practice base outside interests in the original of the basis of statistics professional training and practice base. Students through participation in social practice, to service the social economic and the business development, to absorb nutrients from the practice, the anti-subsidy practice teaching, consolidate the achievements, to teach the skills to use, improve the ability to solve practical problems, contribute to future employment quickly work well done, to lay a good foundation. University-enterprise cooperation is university education teaching and the embodiment of social economic cooperation forum, is an effective way to cultivate innovative talents, and is the specification of the high-quality practical talents training. Local colleges to collaborative innovation as the leading, local materials, actively widen the students' training and practice base, with the government, enterprises 
build long-term, stable relations of cooperation, firmly applied development road.

\section{E. Strengthening Training of Practical Subjects}

Combining teaching reality, teachers can edit practical contents into of subjects according to its complexity level and education requirement and let the students group themselves to carry on the related subject research. Thus subjects can be data statistics analysis by using software, and also be edition and putting into effect of a social survey plan. For example, the consumption survey of students at school and the using ratio of library etc. are effective for training students' cooperative and practical ability, which is beneficial for their future work and study. At the same time, it is effective to cultivate students' innovation and cooperation, language expression, organization and management and communication etc. by practical subject training.

\section{F. Paying Attention on Application of Statistics Tools}

Mastering application of statistics tools is a basic skill that the Statistics majors must be skilled at. Application of statistics tools not only contains operation of statistics software, programming and reading the results, but also and more important the data pre-processing and selecting the statistics mode after considering the problems' background, which requires students have a strong theory base to guide practice. Currently, the statistics software used extensively contains SAS, SPSS, EXCEL, R etc. The statistics major must master one of these statistics tools' basic application, which is useful for the future work and study [5].

\section{G. Strengthening Social Survey Activities}

Social survey is an important teaching program to cultivate and improve students' ability of observing and knowing society, analyzing and solving problems. The students can participate in the survey activities of enterprises and public institutions, and can also set a subject that they are interested in by themselves for surveying or participate in some surveys authorized by the activities sponsors [6]. Through social survey of some hot issues, students can improve comprehensive application of classroom knowledge and skill and the practical operation ability, stepping forwards for the aim of cultivating applied talents.

\section{CONCLUSION}

Above are some views and suggestions about cultivating practical and innovational ability of Applied Statistics majors. Under the transformation background, local colleges and universities only reform the practical teaching model then can ensure the Applied Statistics majors' cultivation aim come true; only reform and bring innovation to teaching methods then can improve studying effect of Applied Statistics majors; and only create ability cultivation supporter and design ability cultivation links then can reach the aim of practical and innovational ability cultivation.

\section{ACKNOWLEDGMENT}

This research was supported by the Project of Undergraduate Teaching's Reform of Guangxi Higher Education (No.2015JGA332).

\section{REFERENCES}

[1] HOU Zong-yi, Applied Statistics Majors Cultivation Model Research of Local Colleges and Universities under the Transformation Background--Taking Hechi University as Sample [J] Education and Teaching Forum, 2016, 11: 62-63.

[2] WANG Lin, YUAN Yan-hua, YU Hai-shu, LIU Hua-nan, Practice Ability Training of Talent of Applied Statistics Specialty [J] Value Engineering 2013, 33: 213-214.

[3] XU Song, LV Hui, Practical and Innovational Ability Cultivation of Applied Statistics Majors [J] Mudanjiang Normal College Journal (Edition of Natural Science) 2014, 02: 56-57.

[4] TANG Yan,REN Yong-tai,FU Li-fang, Practical Teaching Model Research of Statistics Major under the Aim of Applied Talents Cultivation [J] University Education 2013, 16: 96-97.

[5] Hua Huan-huan, Wu Yang Teaching Reform of Training on the Statistics Major Students Application-oriented Talents-Based on the Enhance of Practical Ability [J] 2015,04:111-114 .

[6] PAN Shu-xia, SUN Wang-jie, ZHANG Ruo-dong, Exploration and Practice of Statistical Application Ability Training [J] Journal of Ji Lin Institute of Chemical Technology 2015.02:80-83 